\title{
Does pregnancy increase curve progression in women with scoliosis treated without surgery?
}

\author{
Authors Josh E Schroeder ${ }^{1}$, Joseph R Dettori ${ }^{2}$, Erika Ecker ${ }^{2}$, Leon Kaplan ${ }^{1}$ \\ Institution $\quad{ }^{1}$ Orthopedic Department, Hadassah Hebrew University Medical Center, Jerusalem, Israel \\ ${ }^{2}$ Spectrum Research Inc, Tacoma, Washington, USA
}

\section{ABSTRACT}

Study design: Systematic review.

Study rationale: It is commonly believed that scoliosis treated nonoperatively does not worsen in pregnancy; however, at times patients with scoliosis progress rapidly during these months.

Objective or clinical question: What is the level of evidence to support or deny the claim that scoliosis treated nonoperatively does not worsen in pregnancy?

Methods: A systematic review of the literature was undertaken for articles published through March 2011. PubMed, Cochrane, National Guideline Clearinghouse Databases as well as bibliographies of key articles were searched. Two independent authors reviewed articles. Inclusion and exclusion criteria were set and each article was subject to a predefined quality-rating scheme.

Results: We identified two articles meeting our inclusion criteria. There was no difference in risk of curve progression $>5^{\circ}$ or $>10^{\circ}$ between women who had one or more pregnancies compared with those who had never been pregnant. However, among women who had been treated with an orthosis, those with one or more pregnancies had a higher risk of curve progression $>5^{\circ}$ compared with never-pregnant women: relative risk $=8.1$ (95\% confidence interval: $1.8-35.8)$ in one study and $1.9(95 \%$ confidence interval: $0.8-4.3)$ in the other. While women with more severe curves had a higher risk of curve progression, having one or more pregnancies did not appear to modify the effect of curve severity.

Conclusions: Having one or more pregnancies does not appear to affect curve progression in scoliosis. However, among patients who had prior orthotic treatment, there is some evidence to suggest that women experiencing one or more pregnancies had a higher risk of curve progression compared with never-pregnant women. The overall strength of evidence for this conclusion is low.

This study was not financially supported and the authors have no conflict of interest to disclose. 


\section{STUDY RATIONALE AND CONTEXT}

Scoliosis is a deformity affecting mainly women. Most patients are not operated and sustain an unbalanced spine, which might progress over the years (depending on severity of the curve). Pregnancy is a special event in a woman's life. She undergoes major hormonal, weight, and bodily changes in a short period. These changes lead to modifications in form of temporary hyperelasticity of supportive connective tissues ultimately allowing widening of the pelvic ring for the birth of a child. The conventional wisdom is that scoliosis curves are not affected by pregnancy; however, there have been cases when pregnancy may have been associated with acceleration in curve progression eventually leading to surgical scoliosis correction.

In this study we aim to see if the conventional wisdom stated in textbooks is supported by the medical literature and if there are specific groups of patients who are at increasing risk of curve progression during pregnancy.

\section{OBJECTIVE OR CLINICAL QUESTION}

To systematically search for, critically appraise, and summarize literature evaluating pregnancy as a risk factor for curve progression among women with scoliosis who were treated nonoperatively.

\section{METHODS}

Study design: Systematic review.

Sampling: PubMed, Cochrane Collaboration Database, bibliographies of key articles. Dates searched: through March 3, 2011.

Inclusion criteria: (1) scoliosis treated nonoperatively (eg, brace, observation, physical therapy); (2) women with scoliosis with one or more pregnancies; and (3) women with scoliosis who have never been pregnant.

Exclusion criteria (Fig 1): (1) fusion surgery for scoliosis; (2) studies that only reported outcomes pertaining to complications in pregnancy and childbirth.

\section{Prognostic factors:}

- Primary

- Pregnancy ( $\geq 1$ pregnancy versus never pregnant)

- Secondary

- Severity of curve

- Curve pattern/type

- Treatment (brace or no brace)

\section{Outcomes:}

- Proportion of patients with curve progression $>5^{\circ}$ and $>10^{\circ}$

\section{Analysis:}

Proportions of patients with curve progression at $>5^{\circ}$ and $>10^{\circ}$ were reported as the number of patients exceeding threshold within an exposure group (eg, pregnant or never-pregnant group) divided by the total number of patients within the group. We calculated the relative risk (RR) of curve progression and $95 \%$ confidence intervals (95\% CI) comparing women that had $\geq 1$ pregnancy with women who had no pregnancy. Overall strength of the evidence was assessed using GRADE criteria.

Additional methodological and technical details are provided in the electronic supplemental material at www.aospine.orglebsj 


\section{RESULTS}

From a total of 77 citations, 23 articles evaluating the treatment of scoliosis were selected for full-text review (Fig 1). Of these, only two met the inclusion criteria and were included for analysis. One study evaluated the longterm follow-up of the Milwaukee Brace in both males and females. From that study, we report data on curve progression in a subset of pregnant woman [1]. All patients had idiopathic scoliosis (Table 1). Average follow-up was 7.5 and 11.2 years. One study reported follow-up from the end of bracing to last examination [1] and one from time of initial diagnosis to final follow-up [2]. Both studies are class of evidence III.

Further details on the class of evidence rating for these studies can be found in the supplemental material at www.aospine.orglebsj.

One study reported no difference in risk of curve progression of $>5^{\circ}$ comparing women who experienced one or more pregnancies and those who had never been pregnant, $27 \%$ and $26 \%$, respectively [2]. The risk of curve progression of $>10^{\circ}$ was slightly higher in women who had one or more pregnancies compared with never-pregnant women; however, this was not statistically different, $14 \%$ versus $9 \%$, respectively (Fig 2, Table 2).
Two studies looked at the effect of pregnancy among women who had prior orthotic treatment. The risk of curve progression of $>5^{\circ}$ was greater in women who had been treated with an orthosis and who had one or more pregnancies compared with those who had never been pregnant in both studies: $29 \%$ versus $4 \%(\mathrm{RR}=8.1 ; 95 \%$ CI: $1.8-35.8 ; P=.0017)[1]$, and $27 \%$ versus $14 \%(\mathrm{RR}=1.9$; 95\% CI: $0.8-4.3 ; P=.18$ ) [2] (Fig 3, Table 2). One of the studies also looked at curve progression $>10^{\circ}$ in this treatment population and also found a greater risk among patients with one or more pregnancies versus those who had never been pregnant, $11 \%$ versus $2 \%, \mathrm{RR}=5.95$ (95\% CI, 0.69-51.1) [2].

One study evaluated the effect of pregnancy among women with different curve severities [2] (Table 2). While women with more severe curves had a higher risk of curve progression, having one or more pregnancies did not appear to modify the effect of curve severity: the risk of curve progression $>5^{\circ}$ in women with a curve severity of $>30^{\circ}$ was $34 \%$ in women who had at least one pregnancy and $35 \%$ in those who had never been pregnant.

Having one or more pregnancies did not modify the effect of curve pattern on the risk of curve progression [2] (Table 2).

\section{CLINICAL GUIDELINES}

- None found.

Fig 1 Results of literature search.

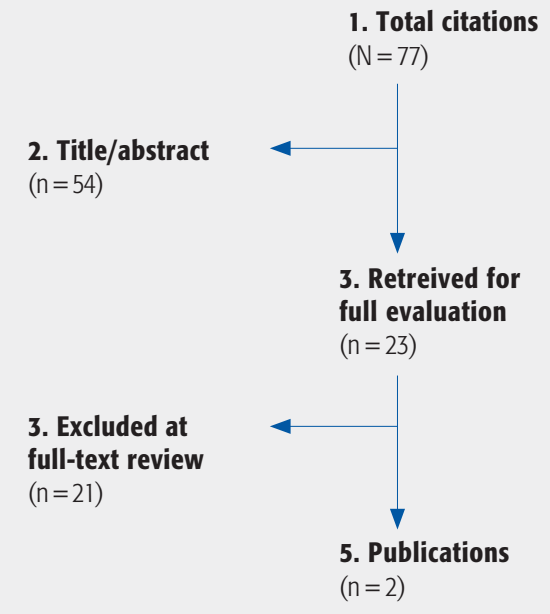

1. Total citations

3. Retreived for full evaluation

$(n=23)$

3. Excluded at full-text review $(n=21)$

5. Publications

$(n=2)$ 
Fig 2 The effect of pregnancy on the risk of scoliosis curve progression $>5^{\circ}$ and $>10^{\circ}$ in patients who had been treated with or without orthosis as reported by Betz et al [2] $(\mathrm{N}=250)$.

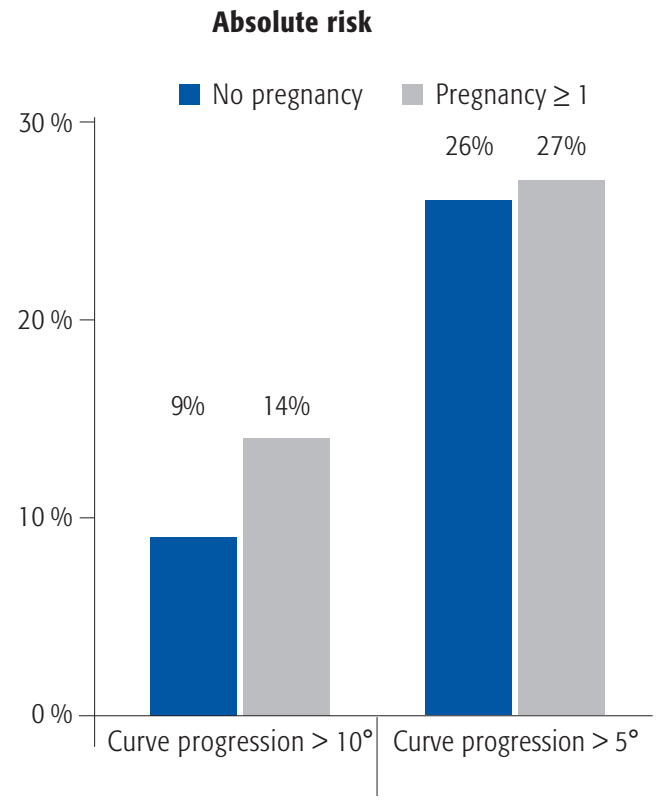

Relative risk (95\% confidence interval)

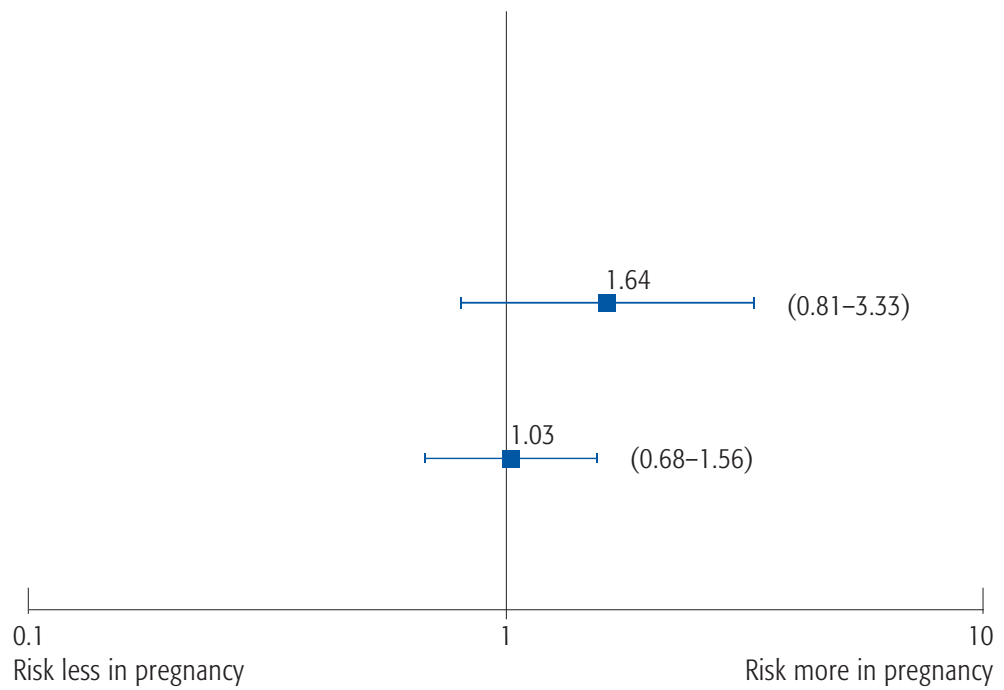

Fig 3 The effect of pregnancy on the risk of scoliosis curve progression $\geq 5^{\circ}$ in patients who had been treated with an orthosis.

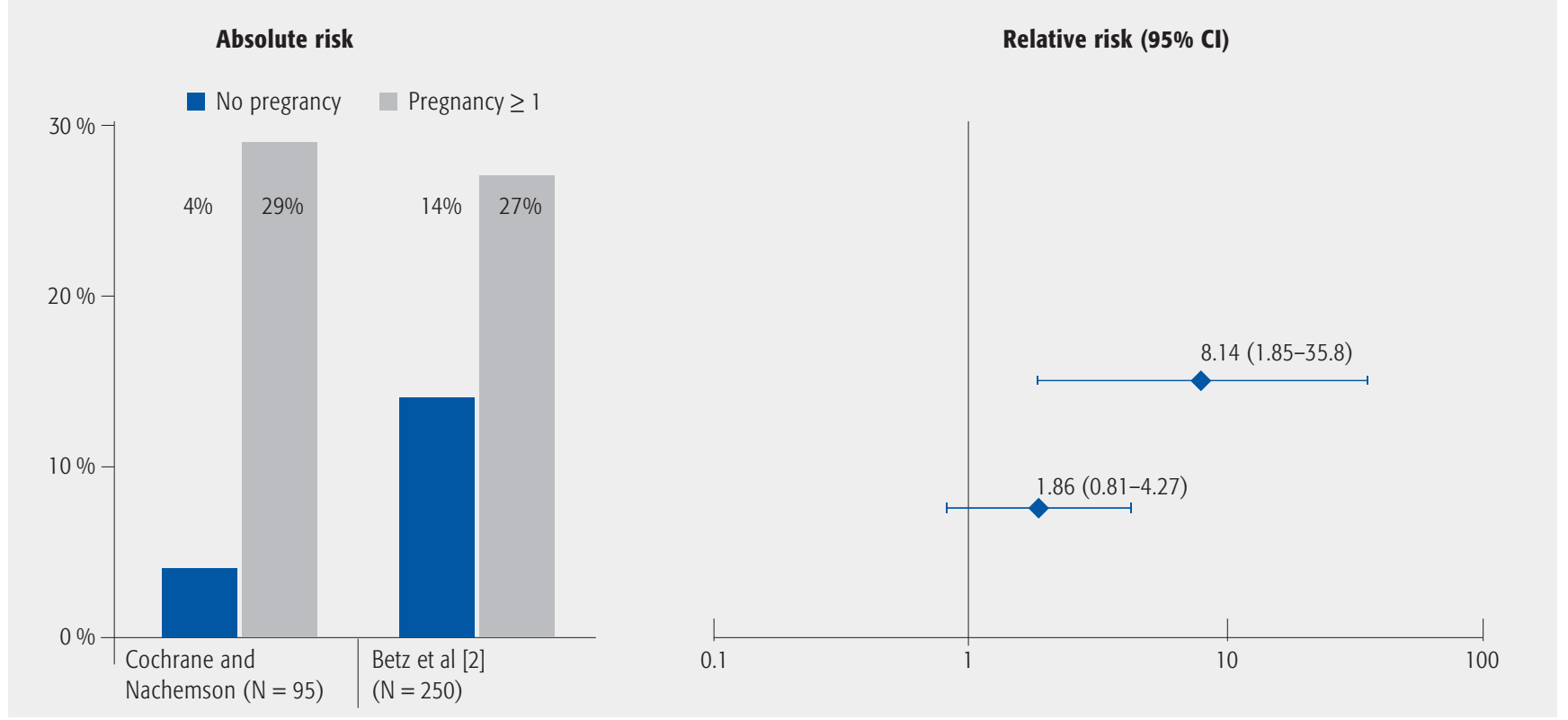


Fig 4 A posteroanterior $x$-ray of the spine of a 21-year old woman. She has a left lumbar curve of $61^{\circ}$ (Cobb angle) with an apex at L1.
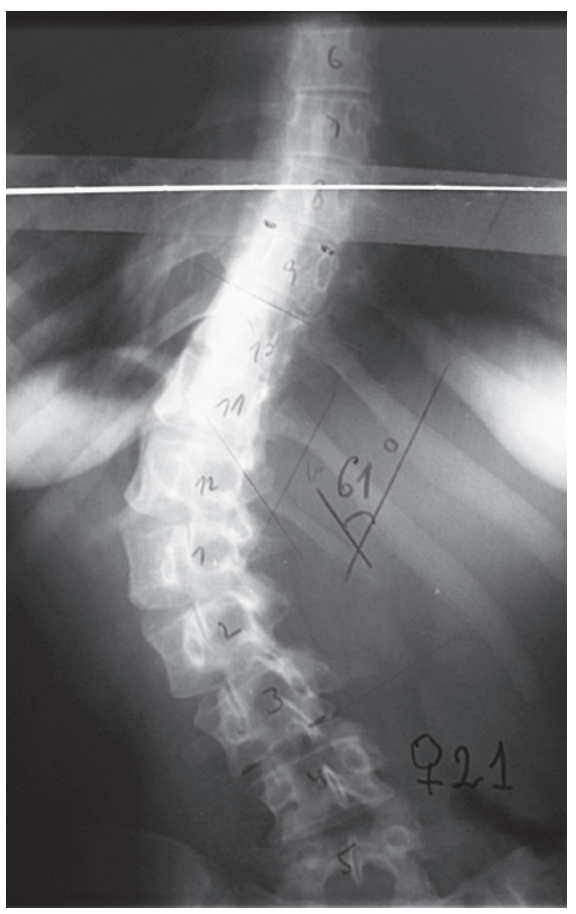

Fig 7 A posteroanterior $x$-ray taken 6 months after posterior fixation of L5-T6.

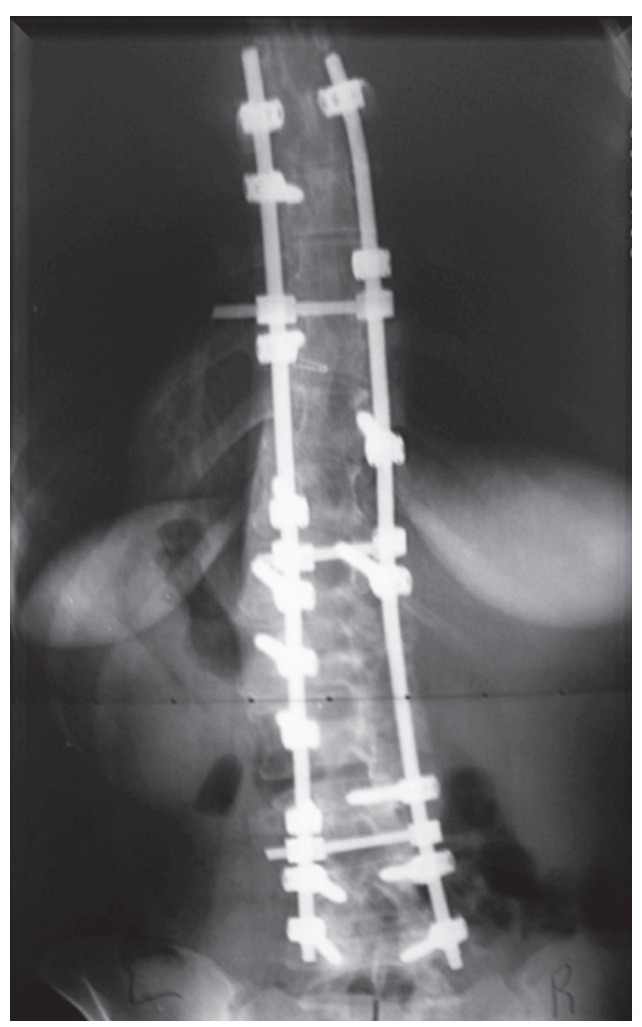

Fig 5 Posterioanterior $x$-ray done after three pregnancies; a worsening of the scoliosis can been seen with a Cobb angle of $78^{\circ}$.

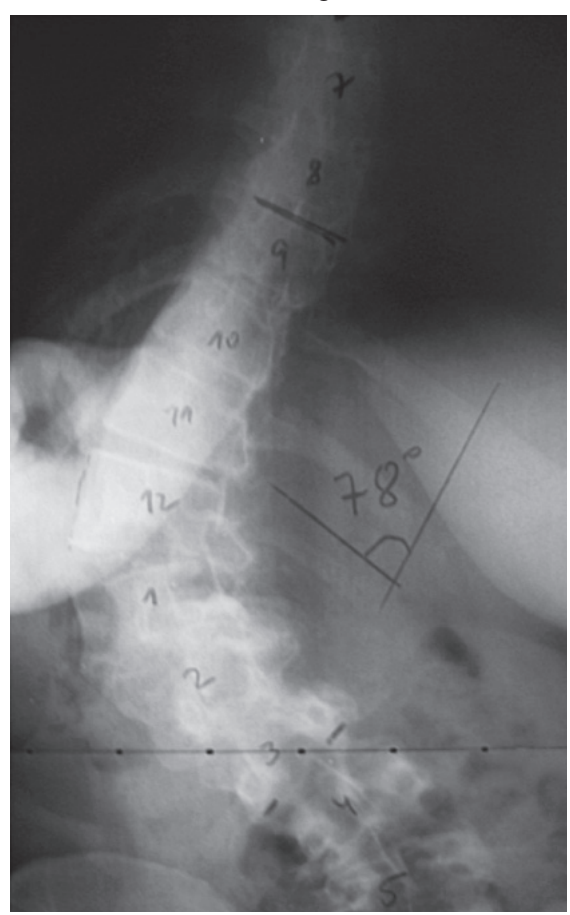

Fig 8 Lateral $x$-ray of the fixation.

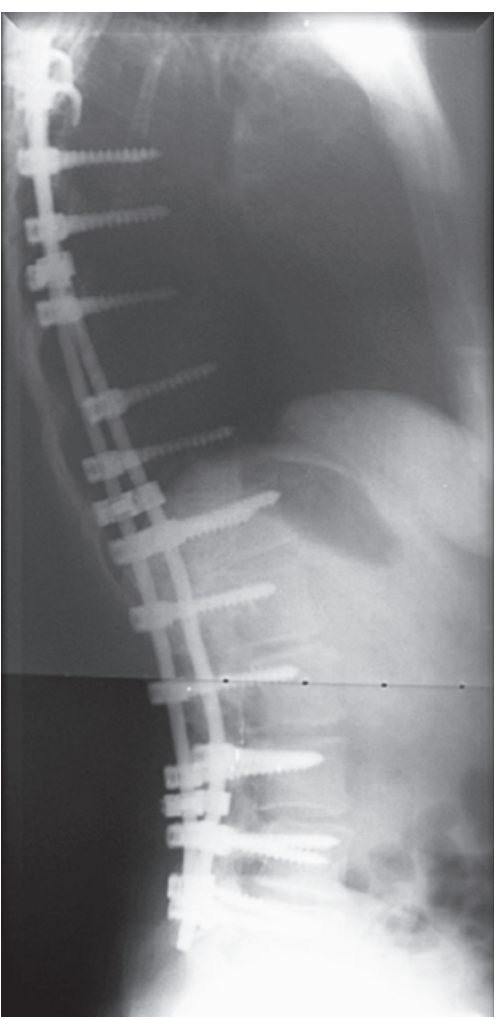

Fig 6 Lateral x-ray showing the kyphotic deformity of the patient.

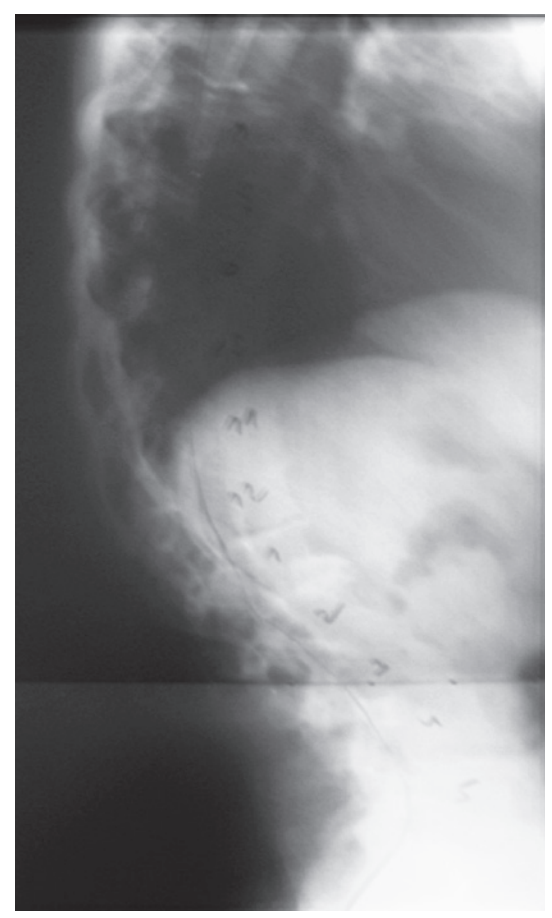

Fig 9 A clinical picture of the patient 2 years after fixation. The patient is satisfied with the result, and works as a hospital nurse.

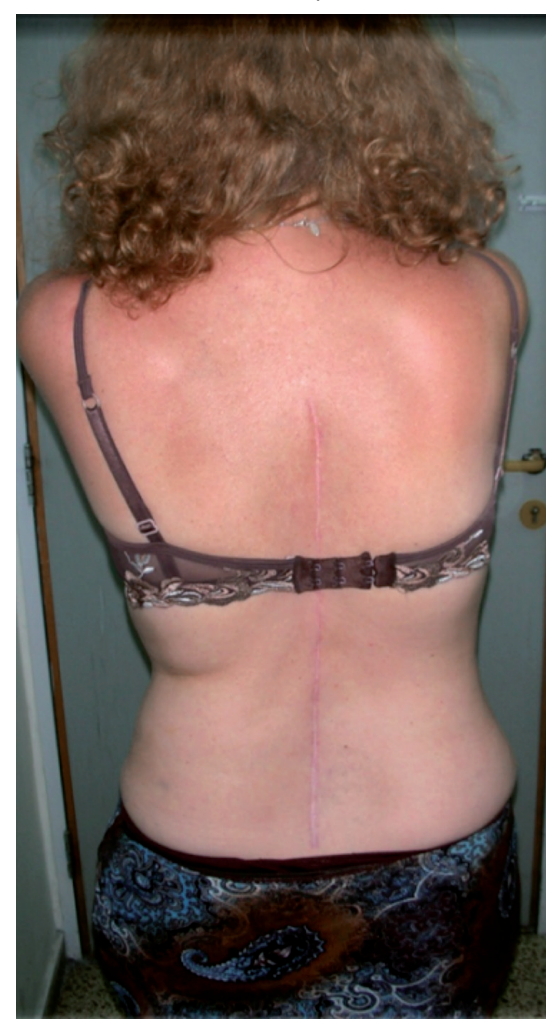


Table 1 Patient and treatment characteristics of included studies investigating the effects of pregnancy on scoliosis*

\begin{tabular}{|c|c|c|c|c|c|}
\hline Author & $\begin{array}{l}\text { Study design } \\
\text { (CoE) }\end{array}$ & $\begin{array}{l}\text { Follow-up } \\
\text { (\% followed) }\end{array}$ & Demographics & $\begin{array}{l}\text { Conservative } \\
\text { treatment }\end{array}$ & Inclusion criteria \\
\hline $\begin{array}{l}\text { Betz et al [2] } \\
1987\end{array}$ & $\begin{array}{l}\text { Retrospective } \\
\text { cohort (chart } \\
\text { review) (III) }\end{array}$ & $\begin{array}{l}\text { From baseline } \\
\text { evaluation (time of } \\
\text { diagnosis) to final } \\
\text { follow-up } \\
\text { examination } \\
\text { - Average } 11.3 \text { y } \\
\text { (\% NR) }\end{array}$ & $\begin{array}{l}\geq 1 \text { pregnancy } \\
-n=112 \\
\text { - Female: } 100 \% \\
\text { - Mean age at final } \\
\text { follow-up: } 26.7 \text { y } \\
\text { Never pregnant } \\
\text { - } n=138 \\
\text { - Female: } 100 \% \\
\text { - Mean age at final } \\
\text { follow-up: } 23.8 \mathrm{y \dagger}\end{array}$ & $\begin{array}{l}\text { Observation } \\
\text { - Pregnancy: } n=75(67 \%) \\
\text { - No pregnancy: } n=83(60 \%) \\
\text { - Orthosis } \\
\text { - Pregnancy: } n=37(33 \%) \\
\text { - No pregnancy: } n=55(40 \%)\end{array}$ & $\begin{array}{l}\text { Inclusion: } \\
\text { - Diagnosis of idiopathic scoliosis } \\
\text { - } \geq 1 \text { x-ray made at a minimum of } 1 \text { year before } \\
\text { reaching skeletal maturity } \\
\text { - } 1 \text { x-ray made at or near the time of skeletal } \\
\text { maturity } \\
\text { - A current x-ray } \\
\text { - Clinical evaluation done specifically for the } \\
\text { purpose of the study }\end{array}$ \\
\hline $\begin{array}{l}\text { Cochrane } \\
\text { and } \\
\text { Nachemson } \\
\text { [1] 1985 }\end{array}$ & $\begin{array}{l}\text { Retrospective } \\
\text { cohort (III) }\end{array}$ & $\begin{array}{l}\text { From end of bracing } \\
\text { to follow-up } \\
\text { examination } \\
-7.5 \text { y (range, } 5-12 \text { y); } \\
\quad(80 \%, n=85 / 95)\end{array}$ & $\begin{array}{l}\text { Total } \\
\text { - n=95 } \\
\text { - Female: 95\%§ } \\
\text { - Mean age: NR } \\
\geq 1 \text { pregnancy§ } \\
\text { - n=28 } \\
\text { - Female: 100\% } \\
\text { - Mean age: NR† } \\
\text { Never pregnant§ } \\
\text { - n=57 } \\
\text { - Female: } 93 \% \\
\text { - Mean age: NR }\end{array}$ & Orthosis (Milwaulkee brace) & $\begin{array}{l}\text { Inclusion } \\
\text { - Adolescent idiopathic scoliosis with no other } \\
\text { related disorders of the spine } \\
\text { - Thoracic, thoracolumbar, or double primary } \\
\text { curves }>24^{\circ} \text { and } \angle 50^{\circ} \text {; lumbar curves }<60^{\circ} \\
\text { - Milwaukee brace treatment began after } \\
10 \text { years old and was completed before } \\
20 \text { years old } \\
\text { - Treatment accomplished at Sahlgren Hospital } \\
\text { under the direction of the first author (JES) } \\
\text { - Minimum follow-up of } 5 \text { years thereafter } \\
\text { - Minimum age of } 22 \text { years at final follow-up }\end{array}$ \\
\hline
\end{tabular}

${ }^{*}$ CoE indicates class of evidence; NR, not reported.

† Mean ages include posterior spinal fusion group: pregnant $(n=63)$ and never pregnant $(n=42)$.

₹ Main focus of this study was the long-term follow-up of the Milwaukee Brace; thus males were included (5\%). However, the effect of pregnancy on

scoliosis was reported in a subgroup of women and those data were used for the purposes of this systematic review.

$\S$ Reflects the number of patients who returned for personal follow-up examination by the second author (JRD) ( $n=85)$.

Table 2 The risk of curve progression in patients with scoliosis who are pregnant compared with those who have never been pregnant stratified by prior treatment type, curve severity, and curve pattern.

\begin{tabular}{|c|c|c|c|c|c|}
\hline & & \multicolumn{2}{|c|}{ Risk of curve progression $>5^{\circ}$} & \multicolumn{2}{|c|}{ Risk of curve progression $>10^{\circ}$} \\
\hline & & $\geq 1$ Pregnancy & Never pregnant & $\geq 1$ Pregnancy & Never pregnant \\
\hline \multirow[t]{13}{*}{ Betz et al [2] 1987} & Treatment & & & & \\
\hline & - No treatment or orthosis & $27 \%(30 / 112)$ & $26 \%(36 / 138)$ & $14 \%(16 / 112)$ & $9 \%(12 / 138)$ \\
\hline & - No treatment only & $27 \%(20 / 75)$ & $34 \%(28 / 83)$ & $9 \%(7 / 75)$ & $11 \%(9 / 83)$ \\
\hline & - Orthosis only & $27 \%(10 / 37)$ & $14 \%(8 / 55)$ & $11 \%(4 / 37)$ & $2 \%(1 / 55)$ \\
\hline & Curve severity & & & & \\
\hline & $-\leq 30^{\circ}$ & $18 \%(9 / 51)$ & $15 \%(9 / 62)$ & $6 \%(3 / 51)$ & $3 \%(2 / 62)$ \\
\hline & $-31^{\circ}-49^{\circ}$ & $29 \%(11 / 38)$ & $26 \%(14 / 53)$ & $13 \%(5 / 38)$ & $6 \%(3 / 53)$ \\
\hline & $-\geq 50^{\circ}$ & $43 \%(10 / 23)$ & $57 \%(13 / 23)$ & $17 \%(4 / 23)$ & $22 \%(5 / 23)$ \\
\hline & Curve pattern & & & & \\
\hline & - Thoracic & $22 \%(7 / 31)$ & $32 \%(17 / 52)$ & $13 \%(4 / 31)$ & $9 \%(5 / 52)$ \\
\hline & - Thoracolumbar & $25 \%(4 / 16)$ & $15 \%(5 / 34)$ & $6 \%(1 / 16)$ & $0 \%(0 / 34)$ \\
\hline & - Lumbar & $28 \%(4 / 14)$ & $16 \%(3 / 19)$ & $0 \%(0 / 14)$ & $10 \%(2 / 19)$ \\
\hline & - Double major & $29 \%(5 / 51)$ & $27 \%(9 / 33)$ & $12 \%(6 / 51)$ & $6 \%(2 / 33)$ \\
\hline \multirow[t]{2}{*}{$\begin{array}{l}\text { Cochrane and } \\
\text { Nachemson [1] } 1985\end{array}$} & Treatment & & & & \\
\hline & - Orthosis & $29 \%(8 / 28)$ & $4 \%(2 / 57)$ & - & - \\
\hline
\end{tabular}




\section{EVIDENCE SUMMARY}

\begin{tabular}{l} 
Question 1: Does pregnancy affect curve progression in scoliosis treated nonoperatively? \\
\hline Outcomes
\end{tabular}

ILLUSTRATIVE CASE (provided by J Schroeder/L Kaplan)

A woman with scoliosis received orthotic treatment during childhood and at 21 years had a left lumbar curve of $61^{\circ}$ (apex at L1) (Fig 4). She got married, had three children (within 5 years), and returned to the clinic with an increased cosmetic deformity and new back pain. A new $\mathrm{x}$-ray showed an increase of the curve to $80^{\circ}$ and a thoracolumbar kypotic deformity (Figs 5 and $\mathbf{6}$ ). After a magnetic resonance imaging was performed that ruled out any intraspinal pathology, the patient underwent posterior spinal fusion from T6 to L5 (Figs 7 and 8 ). Two years postoperatively the patient has a balanced spine and she is back at work as a hospital nurse (Fig 9).

\section{DISCUSSION}

- Strengths: The question was reviewed systematically - Main limitations: Little data is available to answer the question. Other limitations include:

- Small number of studies available to address the issue.

- The two main studies are retrospective (CoE III) and did not account for any confounding variables.

- Loss to follow-up was not reported in one study and was $20 \%$ in the other, possibly biasing the results.

The results from two small retrospective studies suggest that women with one or more pregnancies are not at increased risk of curve progression compared with nonpregnant women. However, there is a suggestion that among patients who had been treated with an orthosis, those with one or more pregnancies showed a greater curve progression for both thresholds $\left(5^{\circ}\right.$ and $\left.10^{\circ}\right)$ than women who had never been pregnant.

One possible explanation for this finding could relate to ligament and muscle weakness that has been shown to occur after years of treatment in a brace [3]. This can have lasting effects for 5-7 years after removal of the brace. Another possible explanation for this difference may be that patients with larger curves and higher risk at baseline are already biased toward brace treatment. If this were true the proportion of patients who progressed $>5^{\circ}$ would be higher among those treated with an orthosis compared with those who had no orthotic treatment. However, we did not find this to be the case in the Betz et al study [2] (Table 2), leading us to conclude that greater initial curve severity was not a confounding factor in this outcome.

One study reported that multiple pregnancies at a young age $(<25$ years) are a risk factor for curve progression [1]. This conclusion is based on the fact that $70 \%$ of the women with a curve progression of $>5^{\circ}$ had multiple pregnancies. However, no data were reported for women with a curve progression of $<5^{\circ}$ and it is possible that the same proportion of women in that group had multiple pregnancies. Without a direct comparison to women without curve progression, this conclusion is unfounded.

In one study, the mean age at final follow-up was 3 years longer in women with one or more pregnancies versus those who had never been pregnant [2]. There is some evidence to suggest that scoliosis progresses by about $1^{\circ}$ a year in adulthood $[4,5]$. In this case, the age difference slightly overestimates the proportion of patients in the pregnancy group that progressed which further suggests pregnancy does not increase the risk of scoliotic curve progression.

In the study by Betz et al [2], although patients underwent $\mathrm{x}$-ray evaluations at five separate time points (ie, ages) during the study, only curve progression at final followup was reported. It would have been informative to know whether the curve progression in these patients happened primarily before skeletal maturity; however, this information was not provided.

A prospective study observing a cohort of women with nonoperated scoliosis is needed to answer the question of the interaction of pregnancy and curve progression. 


\section{REFERENCES}

1. Cochran T, Nachemson A (1985) Long-term anatomic and functional changes in patients with adolescent idiopathic scoliosis treated with the Milwaukee brace. Spine; 10(2):127133.

2. Betz RR, Bunnell WP, Lambrecht-Mulier E, et al (1987) Scoliosis and pregnancy. J Bone Joint Surg Am; 69(1):90-96.

3. Mooney V, Gulick J, Pozos R (2000) A preliminary report on the effect of measured strength training in adolescent idiopathic scoliosis. $J$ Spinal Disord; 13(2):102-107.

4. Edgar MA (1987) The natural history of unfused scoliosis. Orthopedics; 10(6):931-939.

5. Hassan I, Bjerkreim I (1983) Progression in idiopathic scoliosis after conservative treatment. Acta Orthop Scand; 54(1):88-90.

\section{EDITORIAL PERSPECTIVE}

The reviewers congratulate Schroeder and colleagues for selecting an interesting topic with contentious undertones. Our reviewers and the EBSJ editorial staff were surprised that for a topic that is seemingly such an established medical fact ("Scoliosis is not caused or accelerated by pregnancy!") the actual evidence base is rather thin, to put it kindly. The lack of evidence base for determination of a relationship of pregnancy and cure progression in scoliosis is very low that it is difficult to draw any observations, and certainly not to the degree of counseling patients about the influence of pregnancy on their curve progression or eventual treatment needs.

Here are some observations from our reviewers:

- The types of scoliosis (adolescent onset idiopathic, infantile onset idiopathic, congenital variants, adult onset, neuromuscular, and mechanical to name but a few) appears not differentiated in the available literature. In addition, curve types (using Lenke, King, or other classification systems and initial curve magnitude as well as age of first treatment may all be huge factors) in establishing curve progression risks. There could be differences in responses to pregnancy for curve subtypes, location, and magnitude.

- It needs to be emphasized that for obvious reasons, this systematic review assesses progression in adulthood. The Betz and coworkers' study compared progression from baseline of diagnosis, which uses adolescents not adulthood. So the question not answered by the current state of our literature is how much curve progression occurred before adulthood?

- Another unanswered question is what to measure in patients with known scoliosis? Is curve progression expressed in Cobb angles really relevant? Or should we focus on other factors, such as curve decompensation, occurrence rates of back pain expressed as consumption of health resources (such as visits to health professionals for low back pain) or conversion rate of patients to surgically treated backs? The current focus on Cobb angle alone seems not reflective of the actual problem.

There appear to be problems with inclusion of males in the Cochrane review on this topic. This study limitation confounds the results of the "never pregnant" category.

All reviewers agreed with the authors that the question of pregnancy causing curve progression in adulthood cannot be answered based on currently published literature. Moreover, the present approach of using skeletally immature patients as baseline does not provide a suitable platform to approach the cardinal question. A prospective study design with registry-type approach would be more appropriate to answer the question of the interrelation of scoliosis curve progression and pregnancy. 